\title{
Balloon guide catheter improvements in thrombectomy outcomes persist despite advances in intracranial aspiration technology
}

\author{
Jordi Blasco, ${ }^{1}$ Josep Puig, ${ }^{2}$ Pepus Daunis-i-Estadella (D) , ${ }^{3}$ Eva González, ${ }^{4}$ \\ Juan Jose Fondevila Monso, ${ }^{5}$ Xabier Manso, ${ }^{5}$ Rafael Oteros, ${ }^{6}$ Elvira Jimenez-Gomez, ${ }^{6}$ \\ Isabel Bravo Rey, ${ }^{7}$ Pedro Vega, ${ }^{8}$ Eduardo Murias (1) , ${ }^{8}$ Jose Maria Jimenez, ${ }^{8}$ \\ Antonio López-Rueda (D) , ${ }^{9}$ Arturo Renú (D) ," ${ }^{10}$ Sonia Aixut, ${ }^{11}$ Oscar Chirife Chaparro, ${ }^{12}$ \\ Santiago Rosati, ${ }^{13}$ Manuel Moreu (D) , ${ }^{14}$ Sebastian Remollo (D) , ${ }^{15}$ \\ Yeray Aguilar Tejedor, ${ }^{16}$ Mikel Terceño (D) , ${ }^{17,18}$ Antonio Mosqueira (D) , ${ }^{19}$ \\ Raul G Nogueira, ${ }^{20}$ Luis San Roman ${ }^{9}$
}

- Prepublication history for this paper is available online. To view these files, please visit the journal online (http://dx. doi.org/10.1136/neurintsurg2020-017027).

For numbered affiliations see end of article.

Correspondence to Dr Jordi Blasco, Neurointerventional Department C.D.I, Hospital Clinic de Barcelona, Barcelona 08036 Spain; 30018jba@gmail.com

Received 27 October 2020 Revised 4 February 2021 Accepted 8 February 2021 Published Online First 25 February 2021

Check for updates

(C) Author(s) (or their employer(s)) 2021. No commercial re-use. See rights and permissions. Published by BMJ.

To cite: Blasco J, Puig J, Daunis-i-Estadella P, et al. $J$ Neurolntervent Surg 2021:13:773-778.

\section{ABSTRACT \\ Background First-pass effect (FPE) has been} established as a key metric for technical success and strongly correlates with better clinical outcomes. Most data supporting improved outcomes with the use of a balloon guide catheter (BGC) predate the advent of lastgeneration large-bore intracranial aspiration catheters. We aim to evaluate the impact of BGC in FPE and clinical outcomes in a large cohort of patients treated with contemporary technology.

Methods Patients were recruited from the prospectively ongoing ROSSETTI registry. This registry includes all consecutive patients with anterior circulation large-vessel occlusion (LVO) from 10 comprehensive stroke centers in Spain. Demographic, clinical, angiographic, and clinical outcome data were compared between BGC and non$B G C$ groups. FPE was defined as the achievement of mTICI2c-3 after a single device pass.

Results 426 patients were included out of which 271 $(63.62 \%)$ used BCG. BGC-treated patients had higher FPE rate ( $45.8 \%$ vs $27.7 \% ; \mathrm{P}<0.001)$, higher final $\mathrm{mTICI}$ $\geq 2$ c recanalization rate $(76.8 \%$ vs $50.3 \%$, respectively; $\mathrm{P}<0.001)$, shorter procedural time [median (IQR), 30 (19-58) vs 43 (33-71) min; $P<0.001]$, higher NIHSS difference from admission to 24 hours [median (IQR), 8 (2-12) vs $3(0-10) ; P=0.001$ ], and lower mortality rate (17.6\% vs $29.8 \%, P=0.026)$ compared with non-BGC patients. BGC use was an independent predictor of FPE (OR 2.197, 95\% Cl 1.436 to 3.361; $P<0.001)$, and excellent clinical outcome at 3 months (OR $0.34,95 \% \mathrm{Cl}$ 0.17 to $0.68 ; P=0.002$ ).

Conclusions Our results support the benefit of BGC use on angiographic and clinical outcomes in anterior circulation LVO ischemic stroke remain significant even when considering recent improvements in intracranial aspiration technology.

\section{INTRODUCTION}

Several randomized clinical trials have demonstrated the clinical efficacy of mechanical trombectomy (MT) for acute ischemic stroke secondary to large- vessel occlusion (LVO). ${ }^{1-8}$ The ultimate goal of MT is to achieve a fast and complete recanalization, ideally after one single pass (referred to as first-pass effect, FPE). ${ }^{9-11}$ The FPE, an independent predictor of good clinical outcome, has become a new metric for technically successful MT. In this setting, previous studies have reported positive correlation between the use of a balloon guide catheter (BGC) and higher successful recanalization rates, shorter procedure times, better clinical outcomes, and lower risk of mortality. ${ }^{12-24}$

As such, the use of BGCs is recommended in stent-retriever thrombectomy in current guidelines. ${ }^{1}$ However, despite the preponderance of data in favor of BGC use, many neurointerventionists remain reluctant to use BGC due to different concerns including difficulty in navigating the device, the greater potential for groin complications due to the larger required femoral access, risk of carotid dissection, and compatibility of BGC with larger-bore distal aspiration catheters. ${ }^{25}$ Indeed, the rate of BCG use has been only $45 \%-50 \%$ across large thrombectomy registries. ${ }^{12} 26$ Furthermore, most of the existing data supporting the use of BGC predate the advent of last-generation large-bore intracranial aspiration catheters, which are known to be more effective than their smaller caliber predecessors. ${ }^{27}$ Hence, the sustained benefit of BGC has been increasingly questioned in the face of current technology.

The aim of the current study was to investigate the impact of BGC use in the rates of FPE and good clinical outcomes in a large cohort of anterior circulation LVO patients treated with stent retrievers and last-generation large-bore intracranial intermediate aspiration catheters.

\section{MATERIALS AND METHODS}

The ROSSETTI registry is an ongoing investigatorinitiated prospective study recruiting deidentified demographic, clinical presentation, site-adjudicated angiographic, procedural, and outcome data in consecutive patients with acute ischemic stroke treated with MT across 10 Comprehensive Stroke 
Centers in Spain. The main objective of the ROSSETTI registry is to evaluate the efficacy and safety of the different techniques of MT used in anterior circulation LVO. The registry started in June 2019 and therefore incorporates the more recent device technology. The study inclusion criteria are the following: age $\geq 18$ years; confirmed LVO in the anterior circulation (intracranial internal carotid artery, M1, proximal M2); time from last seen well to treatment up to 24 hours, baseline National Institutes of Health Stroke Scale (NIHSS) score $\geq 2$; and premorbid modified Rankin Scale (mRS) score $\leq 2$. All participating centers received institutional review board approval from their respective institutions and patients or representatives signed informed consent. The study data were collected prospectively through an online questionnaire. The type of stent retriever, as long as it was EC approved, was at the discretion of the operator. At the time of the current analysis, 426 patients had completed the 3-month follow-up period and were included in the study. Qualifying patients were categorized according to the use of BGC vs not.

The primary clinical outcome was the rate of excellent clinical outcome, defined as mRS score 0-1 at 90 days (no or minor symptoms but no functional limitations). ${ }^{28}$ The primary technical outcome was the rate of FPE defined as achieving nearcomplete/complete revascularization [modified Thrombolysis in Cerebral Infarction (mTICI $2 \mathrm{c}-3$ )] after single-device and singlepass approach.

The mRS scores at 90 days, mTICI reperfusion scores, symptomatic intracranial hemorrhage (sICH) (ECCASS-II definition), ${ }^{29}$ rates of modified-FPE defined as achieving mTICI 2b-3 after single-device and single-pass approach, final rates of successful (mTICI2b-3) and complete (mTICI 2c-3) reperfusion, and 90-day mortality rate were assessed for the BGC and non-BGC subgroups. Groin puncture to revascularization

Table 1 Univariate comparison of the balloon guide catheter and non-balloon guide catheter groups of patients with anterior circulation stroke

\begin{tabular}{|c|c|c|c|c|}
\hline & $\begin{array}{l}\text { Overall } \\
(n=426)\end{array}$ & $\begin{array}{l}\text { Non-BGC } \\
(n=155,36.38 \%)\end{array}$ & $\begin{array}{l}\text { BGC } \\
(n=271,63.62 \%)\end{array}$ & P-value \\
\hline Age (years), median (IQR) & $76(65 ; 84)$ & $76(65.5 ; 83.5)$ & $76(65 ; 84)$ & 0.747 \\
\hline Female gender, $\mathrm{n}(\%)$ & $219(51.4 \%)$ & $78(50.3 \%)$ & $141(52 \%)$ & 0.735 \\
\hline NIHSS score at admission, median (IQR) & $16(10 ; 20)$ & $16(12 ; 20)$ & $16(10 ; 20)$ & 0.150 \\
\hline ASPECTS at admission, median (IQR) & $9(7 ; 10)$ & $8(7 ; 10)$ & $9(8 ; 10)$ & 0.001 \\
\hline Last time seen well (min), median (IQR) & $248.5(165 ; 502)$ & $287(173 ; 480)$ & $235(160 ; 519)$ & 0.362 \\
\hline IV tPA administered, $\mathrm{n}(\%)$ & & & & $<0.001$ \\
\hline None & $313(73.5)$ & $101(65.2)$ & $212(78.2)$ & \\
\hline Partial dose & $35(8.2)$ & $10(6.5)$ & $25(12.5)$ & \\
\hline Completed dose & $78(18.3)$ & $44(28.4)$ & $34(9.2)$ & \\
\hline General anesthesia, $\mathrm{n}(\%)$ & $130(30.5)$ & $36(23.2)$ & $94(34.7)$ & 0.006 \\
\hline Local anesthesia, n (\%) & $94(22.1)$ & $30(19.4)$ & $64(23.6)$ & \\
\hline Conscious sedation, $\mathrm{n}(\%)$ & $202(47.4)$ & $89(57.4)$ & $113(41.7)$ & \\
\hline Left site occlusion, n (\%) & $225(52.8)$ & $79(51)$ & $146(53.9)$ & 0.563 \\
\hline Level of vessel occlusion, $\mathrm{n}(\%)$ & & & & 0.009 \\
\hline ICA carotid terminus & $73(17.1)$ & $37(23.9)$ & $36(13.3)$ & \\
\hline MCA-M1 & $232(54.8)$ & $83(53.5)$ & $149(55)$ & \\
\hline MCA-M2 & $121(28.4)$ & $35(22.6)$ & $86(31.7)$ & \\
\hline Groin puncture to first run (min), median (IQR) & $6(5 ; 11)$ & $8(5 ; 15)$ & $6(4 ; 10)$ & 0.016 \\
\hline Mechanical thrombectomy (min), median (IQR) & $27(14 ; 51.2)$ & $33(23 ; 53.8)$ & $22.5(12.5 ; 75)$ & $<0.001$ \\
\hline Groin puncture to revascularization (min), median (IQR) & $37(22 ; 63)$ & $43(33 ; 71)$ & $30(19 ; 58)$ & $<0.001$ \\
\hline $\mathrm{FPE}, \mathrm{n}(\%)$ & $167(39.2)$ & $43(27.7)$ & $124(45.8)$ & $<0.001$ \\
\hline mFPE, n (\%) & $221(51.9)$ & $65(29.4)$ & $156(70.6)$ & 0.002 \\
\hline Final number of passes, $\mathrm{n}(\%)$ & $2(1 ; 3)$ & $2(1 ; 3)$ & $1(1 ; 3)$ & 0.051 \\
\hline 1 & $199(46.7)$ & $60(38.7)$ & $139(51.3)$ & \\
\hline 2 & $107(25.1)$ & $48(31.0)$ & $59(21.8)$ & \\
\hline$>2$ & $120(28.2)$ & $47(30.3)$ & $73(26.9)$ & \\
\hline Final $\mathrm{mTICl} \geq 2 \mathrm{~b}, \mathrm{n}(\%)$ & $380(89.2)$ & $134(86.4)$ & $246(90.8)$ & $<0.001$ \\
\hline Final $\mathrm{mTICl} \geq 2 \mathrm{c}, \mathrm{n}(\%)$ & $286(67.1)$ & $78(50.3)$ & $208(76.8)$ & $<0.001$ \\
\hline Symptomatic intracranial hemorrhage, $\mathrm{n}(\%)$ & $31(10.4)$ & $20(14.2)$ & $11(7)$ & 0.041 \\
\hline NIHSS score at 24 hours, median (IQR) & $7(2 ; 14)$ & $10(4 ; 17.5)$ & $4.5(1 ; 12)$ & $<0.001$ \\
\hline Difference of NIHSS from admission to 24 hours, median (IQR) & $6(1 ; 12)$ & $3(0 ; 10)$ & $8(2-12)$ & 0.010 \\
\hline mRS score $0-2$ at 3 months, $\mathrm{n}(\%)$ & $135(56.5)$ & $62(54.4)$ & $73(58.4)$ & 0.532 \\
\hline Mortality, n (\%) & $56(23.4)$ & $34(29.8)$ & $22(17.6)$ & 0.026 \\
\hline
\end{tabular}

ASPECTS, Alberta Stroke Program Early CT Score; BGC, balloon guide catheter; FPE, first-pass effect; ICA, Internal Carotid Artery; IQR, interquartile range; mRS, modified Rankin Scale; mTICI, modified Thrombolysis in Cerebral Infarction; NIHSS, National Institutes of Health Stroke Scale. 

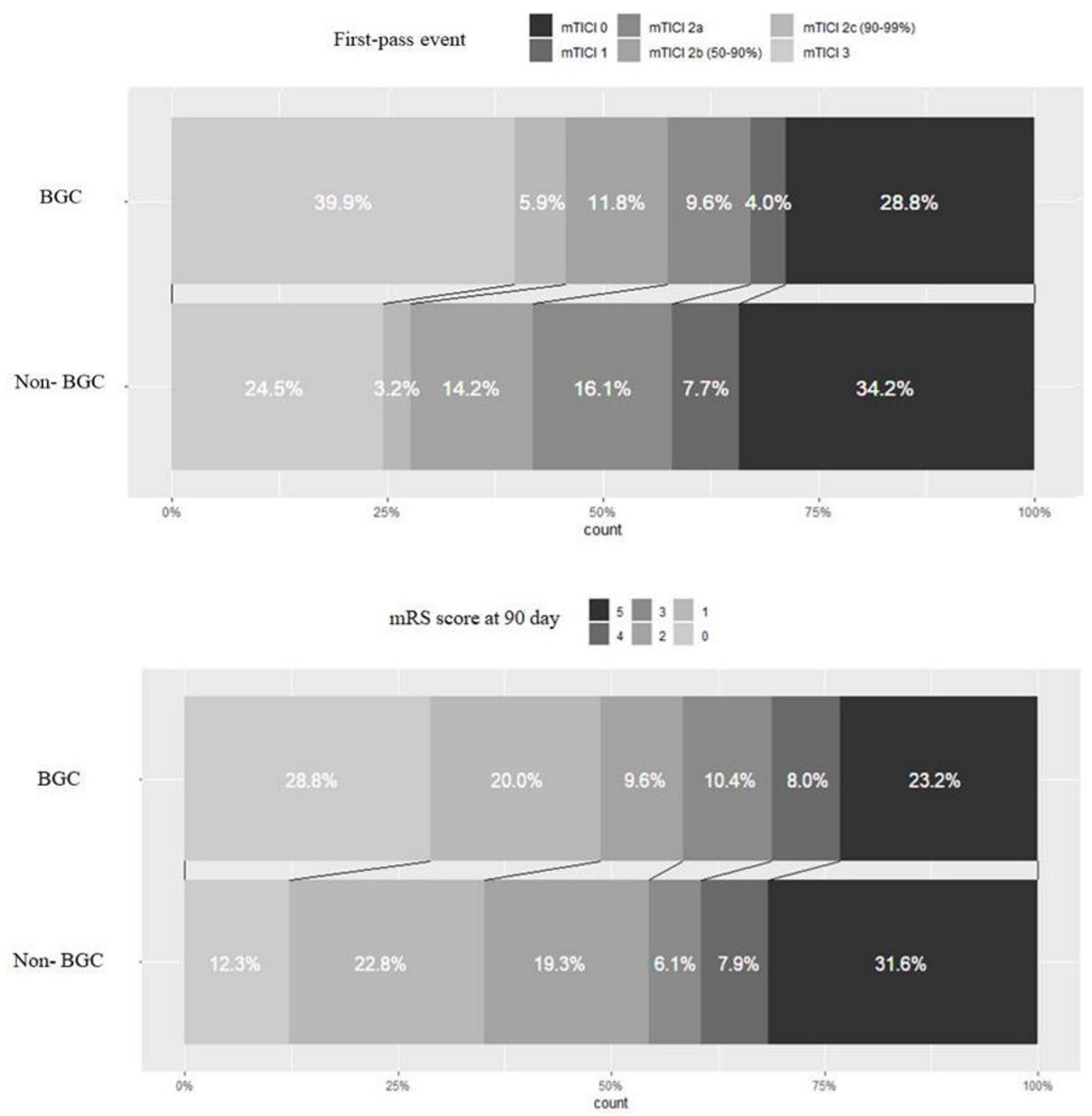

Figure 1 Distribution of recanalization results (above) and clinical outcome (below) comparing the balloon guide catheter and non-balloon guide catheter groups. The $\mathrm{mTICI}$ and $\mathrm{mRSs}$ distributions were not significantly different (Wilcoxon-Mann-Whitney $U$ test, $\mathrm{P}=0.394$ and $\mathrm{P}=0.630$ respectively).

was subcategorized into groin puncture to first run and first run to final revascularization (MT time), and also compared between both groups. Reperfusion scores and sICH evaluation were center- adjudicated by experienced interventionists and functional outcome with the mRS score at 3 months by stroke neurologists blinded to the imaging data.

\section{Statistical analysis}

Demographic, clinical data, procedure details, and angiographic and clinical outcomes were compared according to: non-BGCtreated vs BGC-treated patients; FPE vs non-FPE events; and excellent $(m R S \leq 1)$ vs non-excellent outcome $(m R S>1)$ at 3 months. Chi-square and Fisher's exact tests were used for categorical variables and the student's $t$-test/F-test for continuous variables. Variables with a P-value $<0.05$ in the univariate analyses were entered into the multivariable models. Using binary logistic regression models in multivariate analysis, we evaluated the use of BGC as an independent factor contributing to FPE or/and functional clinical outcome at 3 months. The distribution of ordinal mRS and mTICI scores was analyzed by using the Wilcoxon-Mann-Whitney $U$ test to the cumulative scores. Subjects with mRS or mTICI score missing were excluded from this analysis, and mRS scores 5 and 6 were combined into one category. A P-value $<0.05$ was considered statistically significant. All statistical analyses were performed using $\mathrm{R}$ (version 3.6.1).

\section{RESULTS}

A total of 426 patients (median age, 76 [IQR, 65-84] years; female patients, 51.4\%) were analyzed. Median values for the NIHSS score at admission and Alberta Stroke Program Early CT Score (ASPECTS) were 16 (IQR, 10-20) and 9 (IQR, 7-9), respectively. BGC was used in 271 patients $(63.62 \%)$. The $\mathrm{BGC}$ and non-BGC groups were similar regarding the baseline characteristics except for a 1 point higher ASPECTS score in the BGC group (9 BGC vs 8 non-BGC), the use of general anesthesia which was higher in the $\mathrm{BGC}$ group and the use of rtPA, more frequently administered in the non-BGC patients. In all cases, stent retrievers were used. Adjunctive intracranial aspiration was employed in $37.9 \%$ and $95 \%$ of the BCG and non-BGC patients, respectively. Therefore, stent retriever alone was used in $62.1 \%$ and $5 \%$ of the BCG and non-BGC patients, respectively. Online supplemental table 1 summarizes the $\mathrm{BGC}$ and non-BGC approaches according to the recruiting centers. The inner diameter for the intracranial aspiration catheter was $\geq 0.068$ in $43 \%$ of the cases with the Sofia Plus catheter (ID: 0.070 ") (Microvention, Tustin, California USA) being the most frequently used (23\%). Table 1 summarizes the clinical characteristics of the whole sample. Online supplemental table 2 shows the type and size of the devices used.

The BGC group had shorter groin puncture to revascularization time [30 $\mathrm{min}(19-58)$ vs $43 \mathrm{~min}(33-71) ; \mathrm{P}<0.001]$ and 
Table 2 Comparison between the groups for the first-pass effect

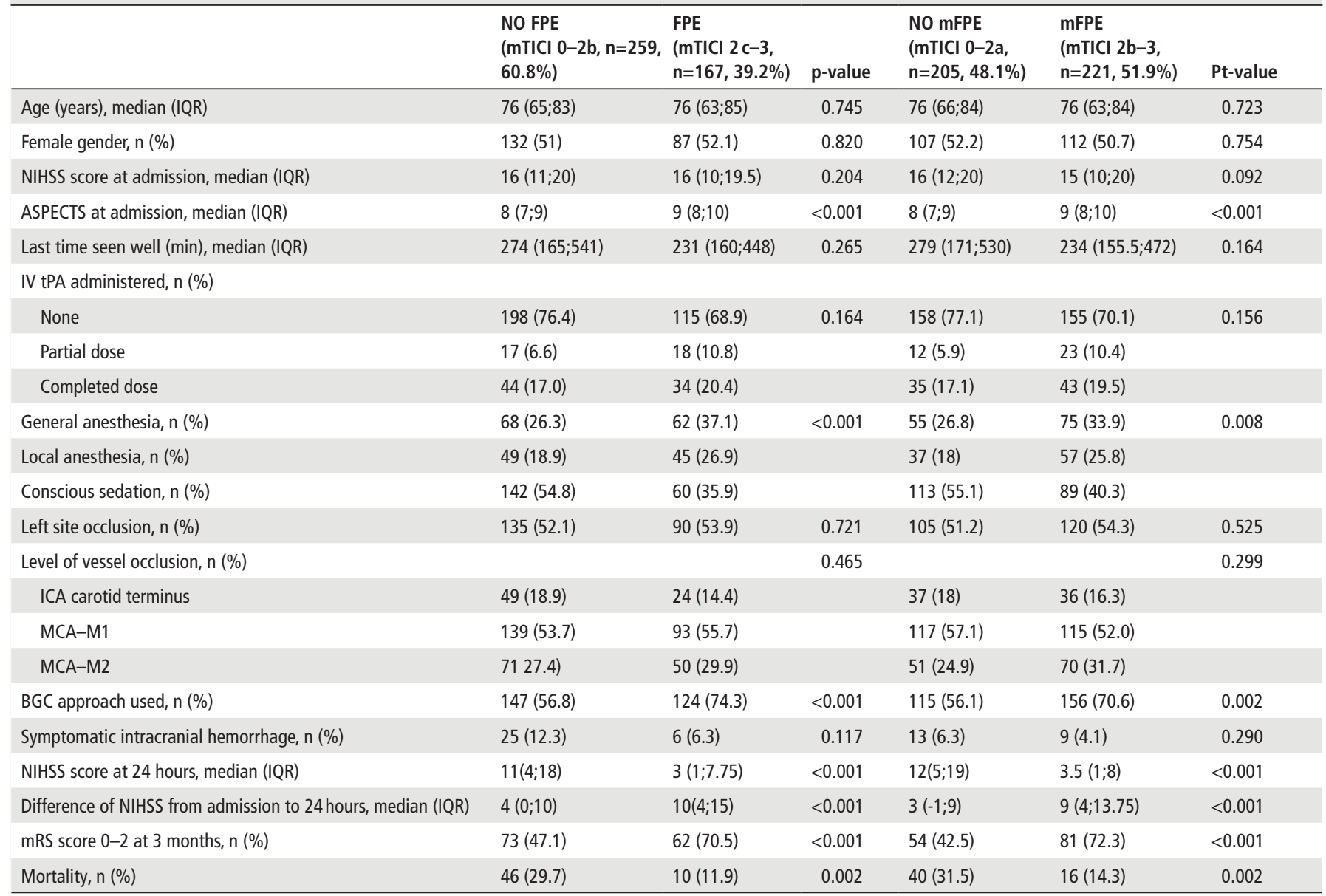

ASPECTS, Alberta Stroke Program Early CT Score; BGC, balloon guide catheter; FPE, first-pass effect; IQR, interquartile range; mRS, modified Rankin Scale; mTICI, modified

Thrombolysis in Cerebral Infarction; NIHSS, National Institutes of Health Stroke Scale.

shorter MT procedural time $[22.5 \mathrm{~min}(12.5-75)$ vs $33 \mathrm{~min}$ (23-53.8); $\mathrm{P}<0.001$ ], with a higher rate of FPE $(45.8 \%$ vs $27.7 \% ; \mathrm{P}<0.001)$ as well as modified-FPE $(70.6 \%$ vs $29.4 \%$; $\mathrm{P}=0.002$ ) compared with the non-BGC group (figure 1). A fewer number of passes [1 (1-3) vs $2(1-3)]$ and higher rate of final successful recanalization (mTICI $\geq 2 \mathrm{c}$ ) was more often achieved in the BGC group $(76.8 \%$ vs $50.3 \% ; \mathrm{P}<0.001)$. There were no statistical significant differences between both groups in terms of good clinical outcome (table 1). The symptomatic hemorrhage rate was higher in the non-BGC group compared with the BGC group ( $7 \%$ vs $14.2 \%, \mathrm{P}=0.041)$. All other clinical outcomes were more favorable in the BGC group (table 1 and figure 1).

The site of LVO was not associated with the achievement of FPE. On univariate analysis, patients who achieved FPE had higher ASPECTS at admission, lower 24h-NIHSS score, higher use of general anesthesia, higher use of BGC, higher difference between NIHSS score at baseline vs 24 hours, better functional outcome at 3 months, and lower mortality (tables 2 and 3 ).

Good clinical outcome at 3 months was higher in younger patients and those with lower NIHSS score at baseline, higher ASPECTS at admission, lower procedure time, fewer number of passes, and higher FPE rate. Good clinical outcome at 3 months was also more common in patients with lower NIHSS score at 24 hours [4 (IQR1-8) vs 16 (9-22)] (table 3).

Multivariate analysis demonstrated that BGC use (OR 2.19; $95 \% \mathrm{CI}, 1.43$ to $3.36 ; \mathrm{P}<0.001$ ) was independently associated with FPE. The predictors of independent functional outcome at 3 months were BGC use (OR 0.34; 95\% CI, 0.17 to 0.68 ; $\mathrm{P}=0.002)$, NIHSS score at 24 hours (OR $1.52 ; 95 \% \mathrm{CI}, 1.31$ to $1.76 ; \mathrm{P}<0.001)$, and number of passes (OR $1.58 ; 95 \% \mathrm{CI}, 1.16$ to $2.13 ; \mathrm{P}=0.003$ ).

\section{DISCUSSION}

In this interim analysis of the ongoing ROSSETTI registry involving a large sample cohort of acute stroke patients with LVO treated with different updated or state-of-the-art stent retriever endovascular approaches, we confirmed that BGC benefits with improved FPE and clinical outcome persist even with the use of the most modern aspiration catheters. Although state-of-the-art distal access catheters were used in 95\% of the procedures performed in the non-BGC group, procedures performed with BGC achieved faster procedure times by increasing the rate of FPE and lowering the number of passes required.

Our results are in line with other previous BGC clinical studies. Recently, Baek et al found that the use of BGC was associated with successful recanalization and favorable outcome, independently of the type of first-line endovascular modality used, whether stent retriever or thromboaspiration. ${ }^{21}$ The North American Solitaire Stent Retriever Acute Stroke (NASA) registry also demonstrated improved clinical outcome and reperfusion scores with the BGC group compared with the non-BGC group. ${ }^{12}$ In a subanalysis of 87 patients from the SWIFT PRIME randomized trial, the authors demonstrated smaller final infarct volumes and improved reperfusion scores in the BGC group. ${ }^{13}$ In 
Table 3 Comparison of the groups according to the functional outcome at 3 months

\begin{tabular}{|c|c|c|c|}
\hline & $\begin{array}{l}\text { Good functional outcome } \\
\text { (mRS } \leq 1, n=101)\end{array}$ & $\begin{array}{l}\text { Poor functional outcome } \\
\text { (mRS }>1, n=138)\end{array}$ & P-value \\
\hline Age (years), median (IQR) & $72(63 ; 81)$ & $76(63.25 ; 84)$ & 0.114 \\
\hline Female gender, $\mathrm{n}(\%)$ & $54(53.5)$ & $70(50.7)$ & 0.675 \\
\hline NIHSS score at admission, median (IQR) & $13(7 ; 19)$ & $17(12 ; 21)$ & $<0.001$ \\
\hline ASPECTS at admission, median (IQR) & $10(8 ; 10)$ & $8(7 ; 9)$ & $<0.001$ \\
\hline Last time seen well (min), median (IQR) & $252(159.75 ; 491.75)$ & $289(167.75 ; 540.25)$ & 0.578 \\
\hline IV tPA administered, $\mathrm{n}(\%)$ & & & 0.575 \\
\hline None & $70(69.3)$ & $104(75.4)$ & \\
\hline Partial dose & $5(5.0)$ & $5(3.6)$ & \\
\hline Completed dose & $26(25.7)$ & $29(21.0)$ & \\
\hline General anesthesia, $\mathrm{n}(\%)$ & $51(50.5)$ & $50(36.2)$ & 0.062 \\
\hline Local anesthesia, $\mathrm{n}(\%)$ & $13(12.9)$ & $29(21.0)$ & \\
\hline Conscious sedation, $\mathrm{n}(\%)$ & $37(36.6)$ & $59(42.8)$ & \\
\hline Left site occlusion, $\mathrm{n}(\%)$ & $53(52.5)$ & $74(53.6)$ & 0.861 \\
\hline Level of vessel occlusion, n (\%) & & & 0.117 \\
\hline ICA carotid terminus & $16(15.8)$ & $32(23.2)$ & \\
\hline MCA-M1 & $53(52.5)$ & $77(55.8)$ & \\
\hline MCA-M2 & $32(31.7)$ & $29(21.0)$ & \\
\hline BGC approach used, n (\%) & $61(60.4)$ & $64(46.4)$ & 0.032 \\
\hline Non-BGC approach used, $\mathrm{n}(\%)$ & $40(39.6)$ & $74(53.6)$ & \\
\hline Groin puncture to first run (min), median (IQR) & $6(4 ; 10)$ & $6(5 ; 11)$ & 0.207 \\
\hline Mechanical thrombectomy (min), median (IQR) & $22(10 ; 35)$ & $39(23,63)$ & $<0.001$ \\
\hline Groin puncture to revascularization (min), median (IQR) & $29.5(17.75 ; 45)$ & $49.5(32 ; 80.75)$ & $<0.001$ \\
\hline $\mathrm{FPE}, \mathrm{n}(\%)$ & $65(64.4)$ & $47(34.1)$ & $<0.001$ \\
\hline Final number of passes, $\mathrm{n}(\%)$ & & & 0.002 \\
\hline 1 & $59(58.4)$ & $46(33.3)$ & \\
\hline 2 & $25(24.8)$ & $39(28.3)$ & \\
\hline$>2$ & $17(16.8)$ & $53(38.3)$ & \\
\hline Final mTICI score, $n(\%)$ & & & $<0.001$ \\
\hline Final $\mathrm{mTICI} \geq 2 \mathrm{~b}, \mathrm{n}(\%)$ & $100(99)$ & $108(78.3)$ & \\
\hline Final $\mathrm{mTICl} \geq 2 \mathrm{c}, \mathrm{n}(\%)$ & $83(82.2)$ & $60(43.5)$ & \\
\hline Symptomatic intracranial hemorrhage, $n(\%)$ & $2(2.0)$ & $11(8.0)$ & 0.044 \\
\hline NIHSS score at 24 hours, median (IQR) & $2(1 ; 6)$ & $12.5(7 ; 21)$ & $<0.001$ \\
\hline Difference of NIHSS from admission to 24 hours, median (IQR) & $9(4 ; 14)$ & $1.5(-1 ; 7)$ & $<0.001$ \\
\hline Mortality, n (\%) & $0(0)$ & $56(46.4)$ & $<0.001$ \\
\hline
\end{tabular}

ASPECTS, Alberta Stroke Program Early CT Score; BGC, balloon guide catheter; FPE, first-pass effect; IQR, interquartile range; mRS, modified Rankin Scale; mTICI, modified Thrombolysis in Cerebral Infarction; NIHSS, National Institutes of Health Stroke Scale.

the ESCAPE trial, the use of a BGC was associated with shorter reperfusion time by $21 \%$ (8 minutes). ${ }^{30}$ Likewise, Velasco et a $1^{14}$ demonstrated higher successful reperfusion with the BGC $(89 \%$ vs 68\%) and shorter procedure duration time in a sample of 183 patients. In another recent analysis, the use of the BGC in the Trevo Stent-Retriever Acute Stroke (TRACK) registry was also associated with lower mortality. ${ }^{30}$ Against this background, the 2018 American Heart Association guidelines recommended that the use of a BGC rather than a cervical guide catheter alone in conjunction with stent retrievers may be beneficial (class IIa; level of evidence C). ${ }^{1}$ Almallouhi et al have also reported the technical feasibility and safety of the transradial approach for neuroendovascular procedures. ${ }^{31}$

The FPE is now considered the benchmark of successful MT. ${ }^{10}$ We found that BGC was an independent predictor of FPE. In a similar way, in the NASA study, FPE was more frequently associated with BGC use and was also an independent predictor of good clinical outcome. ${ }^{12}$ Similar to our study, a meta-analysis of BGC studies including 2022 patients also demonstrated that the BGC group showed higher odds of FPE (OR 2.1, 95\% CI 1.65 to 2.55). ${ }^{30}$ However, in the TRACK BGC subanalysis, the FPE was not significantly different between the BGC and non-BGC groups. ${ }^{24}$ In contrast to previous studies, we found that the FPE was not associated with either the site of LVO or the NIHSS at baseline. Demographic and clinical variables, including NIHSS score at admission and last time seen well, seemed relatively well balanced between the BGC and non-BGC groups, improving the performance comparison.

Several in-vitro and animal model BGC-related studies have shown why this device offers a multi-faceted approach 
for clot retrieval for further understanding mechanisms of thrombectomy optimization. The pivotal point is that the antegrade flow arrest and concurrent aspiration at the balloon guide reduce migration of the entrapped thrombus or fragmented clots extracted by the stent retriever. ${ }^{30}$ Recently, it has been also demonstrated that the use of a BGC provided reliable flow arrest and flow reversal with manual syringe aspiration, whereas aspiration with a conventional $8 \mathrm{~F}$ guide catheter resulted in either collapse of the vessel or oscillatory flow, which may permit antegrade flow. ${ }^{30}$

This study has several limitations. There was no independent adjudication of the clinical outcome and angiographic results for each patient. The decision to use BGC as first option was determined by the internal protocols of each center. Experienced operators might be more likely to choose the use of BGC than less experienced ones. ${ }^{21}$ In fact, it has been suggested that operators' proficiency might be a confounder affecting the use of BGC and/or the treatment outcomes independently of the use of BGC. Although shorter times for MT and from groin puncture to revascularization were seen in the FPE cohort, the time from groin puncture to first run was similar between cohorts. This might indicate that the experience of the different neurointerventionists may be comparable. It has been shown previously that establishing a competitive environment and publicly presenting and discussing procedural times is also an effective and costefficient way of improving procedural times. ${ }^{32}$

\section{CONCLUSION}

Our results demonstrated that the use of BGC in a real-life scenario resulted in a higher rate of FPE success as well as better clinical outcome in acute stroke patients with anterior circulation LVO. Randomized clinical trials to evaluate these findings may be important, along with the role of validating the BGC as a safe and effective option to minimize the number of passes during intervention.

\section{Author affiliations}

'Neurointerventional Department CDI, Hospital Clinic de Barcelona, Barcelona, Catalunya, Spain

${ }^{2}$ IDI-Radiology, Hospital Universitari de Girona Doctor Josep Trueta, Girona,

Catalunya, Spain

${ }^{3}$ Department of Computer Science, Applied Mathematics and Statistics, University of Girona, Girona, Catalunya, Spain

${ }^{4}$ Interventional Neuroradiology, Radiology, Cruces University Hospital, Barakaldo, País Vasco, Spain

${ }^{5}$ Interventional Neuroradiology, Radiology, Hospital Universitario Cruces, Bilbao, País Vasco, Spain

${ }^{6}$ Diagnostic and Therapeutical Neuroradiology Unit, Reina Sofia University Hospital, Cordoba, Andalucía, Spain

${ }^{7}$ Neurorradiologia, Reina Sofia University Hospital, Cordoba, Andalucía, Spain

${ }^{8}$ Radiology, HUCA, Oviedo, Asturias, Spain

${ }^{9}$ Interventional Neuroradiology, Hospital Clinic de Barcelona, Barcelona, Catalunya, Spain

${ }^{10}$ Comprehensive Stroke Unit, Hospital Clinic de Barcelona, Barcelona, Spain

${ }^{11}$ Neuroradiology, Bellvitge University Hospital, L'Hospitalet de Llobregat, Catalunya, Spain

${ }^{12}$ Interventional Neuroradiology, Hospital Universitari de Bellvitge, L'Hospitalet de Llobregat, Spain

${ }^{13}$ Department of Radiology, Clinical San Carlos Hospital, Hospital Clinico

Universitario San Carlos, Madrid, Spain

${ }^{14}$ Neurointerventional Unit, Hospital Clinico Universitario San Carlos, Madrid, Spain

${ }^{15}$ Interventional Neuroradiology Unit, University Hospital Germans Trias i Pujol,

Badalona, Catalunya, Spain

${ }^{16}$ Radiology Department, Hospital Universitario Insular de Gran Canaria, Las Palmas de Gran Canaria, Canarias, Spain

${ }^{17}$ Stroke Unit, Department of Neurology, Hospital Universitari de Girona Doctor Josep Trueta, Girona, Spain

${ }^{18}$ Interventional Neuroradiology Unit, Hospital Universitari Germans Trias i Pujol, Badalona, Spain
${ }^{19}$ Neuroradiology Department, Complexo Hospitalario Universitario de Santiago de Compostela, Santiago de Compostela, Galicia, Spain

${ }^{20}$ Neurology and Interventional Neuroradiology, Emory University School of Medicine, Atlanta, Georgia, USA

Twitter Antonio López-Rueda @AntonioLR81, Arturo Renú @ictusclinic, Oscar Chirife Chaparro@oscarsabino, Manuel Moreu @manumoreu and Sebastian Remollo@Sremollo

Collaborators Ana Caicedo Marin, Data Manager, Hospital Clinic of Barcelona; Federico Zarco Contreras, Neurointerventional Department, CDI.

Contributors All authors contributed equally to the design, writting, and reviewing of the manuscript.

Funding The authors have not declared a specific grant for this research from any funding agency in the public, commercial, or not-for-profit sectors.

Competing interests None declared.

Patient consent for publication Not required.

Ethics approval ROSSETTI Registry has been approved by the IEC of Hospital Clinic of Barcelona HCB/2019/0152.

Provenance and peer review Not commissioned; externally peer reviewed.

Supplemental material This content has been supplied by the author(s). It has not been vetted by BMJ Publishing Group Limited (BMJ) and may not have been peer-reviewed. Any opinions or recommendations discussed are solely those of the author(s) and are not endorsed by BMJ. BMJ disclaims all liability and responsibility arising from any reliance placed on the content. Where the content includes any translated material, BMJ does not warrant the accuracy and reliability of the translations (including but not limited to local regulations, clinical guidelines, terminology, drug names and drug dosages), and is not responsible for any error and/or omissions arising from translation and adaptation or otherwise.

\section{ORCID iDs}

Pepus Daunis-i-Estadella http://orcid.org/0000-0001-6134-9255

Eduardo Murias http://orcid.org/0000-0002-3678-384X

Antonio López-Rueda http://orcid.org/0000-0001-7914-9948

Arturo Renú http://orcid.org/0000-0001-9169-6856

Manuel Moreu http://orcid.org/0000-0002-9001-0661

Sebastian Remollo http://orcid.org/0000-0002-8514-5529

Mikel Terceño http://orcid.org/0000-0001-5532-5329

Antonio Mosqueira http://orcid.org/0000-0003-0345-2486

\section{REFERENCES}

1 Powers WJ, Rabinstein AA, Ackerson T, et al. 2018 guidelines for the early management of patients with acute ischemic stroke: a guideline for healthcare professionals from the American Heart Association/American Stroke Association. Stroke 2018;49:e46-110.

2 Campbell BCV, Hill MD, Rubiera M, et al. Safety and efficacy of Solitaire stent thrombectomy: individual patient data meta-analysis of randomized trials. Stroke 2016:47:798-806.

3 Campbell BCV, Mitchell PJ, Kleinig TJ, et al. Endovascular therapy for ischemic stroke with perfusion-imaging selection. N Engl J Med 2015;372:1009-18.

4 Goyal M, Demchuk AM, Menon BK, et al. Randomized assessment of rapid endovascular treatment of ischemic stroke. N Engl J Med 2015;372:1019-30.

5 Jovin TG, Chamorro A, Cobo E, et al. Thrombectomy within 8 hours after symptom onset in ischemic stroke. N Engl J Med 2015;372:2296-306.

6 Saver JL, Goyal M, Bonafe A, et al. Stent-retriever thrombectomy after intravenous t-PA vs. t-PA alone in stroke. N Eng/ J Med 2015;372:2285-95.

7 Berkhemer OA, Fransen PSS, Beumer D, et al. A randomized trial of intraarterial treatment for acute ischemic stroke. N Engl J Med 2015;372:11-20.

8 Vidale S, Longoni M, Valvassori L, et al. Mechanical thrombectomy in strokes with large-vessel occlusion beyond 6 hours: a pooled analysis of randomized trials. J Clin Neurol 2018;14:407-12.

9 Zaidat 00, Suarez Jl, Sunshine JL, et al. Thrombolytic therapy of acute ischemic stroke: correlation of angiographic recanalization with clinical outcome. AJNR Am J Neuroradiol 2005;26:880-4

10 Zaidat 00, Castonguay AC, Linfante I. First pass effect: a new measure for stroke thrombectomy devices. Stroke 2018:49:660-6.

11 Rha J-H, Saver JL. The impact of recanalization on ischemic stroke outcome: a metaanalysis. Stroke 2007:38:967-73.

12 Nguyen TN, Malisch T, Castonguay AC. Balloon guide catheter improves revascularization and clinical outcomes with the Solitaire device: analysis of the North American Solitaire Acute Stroke Registry. Stroke 2014;45:141-5.

13 Pereira V, Siddiqui A, Jovin T, et al. P-016 role of balloon guiding catheter in mechanical thrombectomy using stentretrivers subgroup analysis of swift prime: Abstract P-016 Table 1. J Neurointerv Surg 2015;7:A30. 
14 Velasco A, Buerke B, Stracke CP, et al. Comparison of a balloon guide catheter and a non-balloon guide catheter for mechanical thrombectomy. Radiology 2016;280:169-76.

15 Zaidat O, Liebeskind D, Jahan R, et al. 0-005 Influence of balloon, conventional, or distal catheters on angiographic and technical outcomes in STRATIS. J Neurointerv Surg 2016;8:A3-4.

16 Zaidat O, Froehler MT, Aziz-Sulta MA. LBP2 influence of balloon, conventional or distal catheters on angiographic and clinical outcomes in the Stratis registry. Stroke 2016;48:LBP2:A3-4.

17 Lee $\mathrm{DH}$, Sung JH, Kim SU, et al. Effective use of balloon guide catheters in reducing incidence of mechanical thrombectomy related distal embolization. Acta Neurochir 2017;159:1671-7.

18 Oh J-S, Yoon S-M, Shim J-J, et al. Efficacy of balloon-guiding catheter for mechanical thrombectomy in patients with anterior circulation ischemic stroke. J Korean Neurosurg Soc 2017;60:155-64.

19 Maegerlein C, Mönch S, Boeckh-Behrens T, et al. PROTECT: PRoximal balloon Occlusion TogEther with direCt Thrombus aspiration during stent retriever thrombectomy - evaluation of a double embolic protection approach in endovascular stroke treatment. J Neurointerv Surg 2018;10:751-5.

20 Kammerer S, du Mesnil de Rochemont R, Wagner M, et al. Efficacy of mechanical thrombectomy using stent retriever and balloon-guiding catheter. Cardiovasc Intervent Radiol 2018;41:699-705.

21 Baek J-H, Kim BM, Kang D-H, et al. Balloon guide catheter is beneficial in endovascular treatment regardless of mechanical recanalization modality. Stroke 2019:50:1490-6.

22 Zaidat 00, Mueller-Kronast NH, Hassan AE, et al. Impact of balloon guide catheter use on clinical and angiographic outcomes in the STRATIS stroke thrombectomy registry. Stroke 2019;50:697-704.
$23 \mathrm{Kim} \mathrm{SH}$, Choi JH, Kang MJ, et al. Efficacy of combining proximal balloon guiding catheter and distal access catheter in thrombectomy with stent retriever for anterior circulation ischemic stroke. J Korean Neurosurg Soc 2019;62:405-13.

24 Nguyen TN, Castonguay AC, Nogueira RG, et al. Effect of balloon guide catheter on clinical outcomes and reperfusion in Trevo thrombectomy. J Neurointerv Surg 2019;11:861-5.

25 Shah VA, Martin CO, Hawkins AM, et al. Groin complications in endovascular mechanical thrombectomy for acute ischemic stroke: a 10-year single center experience. J Neurointerv Surg 2016;8:568-70.

26 Zaidat 00, Castonguay AC, Nogueira RG, et al. TREVO stent-retriever mechanical thrombectomy for acute ischemic stroke secondary to large vessel occlusion registry. $J$ Neurointerv Surg 2018;10:516-24.

27 Arslanian RA, Marosfoi M, Caroff J, et al. Complete clot ingestion with cyclical adapt increases first-pass recanalization and reduces distal embolization. J Neurointerv Surg 2019;11:931-6.

28 Broderick JP, Adeoye O, Elm J. Evolution of the modified Rankin Scale and its use in future stroke trials. Stroke 2017;48:2007-12.

29 Hacke W, Kaste M, Fieschi C, et al. Randomised double-blind placebo-controlled trial of thrombolytic therapy with intravenous alteplase in acute ischaemic stroke (ECASS II). second European-Australasian acute stroke study Investigators. Lancet 1998;352:1245-51.

30 Chueh J-Y, Kühn AL, Puri AS, et al. Reduction in distal emboli with proximal flow control during mechanical thrombectomy: a quantitative in vitro study. Stroke 2013:44:1396-401.

31 Almallouhi E, Al Kasab S, Sattur MG, et al. Incorporation of transradial approach in neuroendovascular procedures: defining benchmarks for rates of complications and conversion to femoral access. J Neurointerv Surg 2020;12:1122-6.

32 Mertens J, Singh $\mathrm{R}$, Reich $\mathrm{A}$, et al. A competitive clinical environment improves procedural times in endovascular stroke treatment. J Neurointerv Surg 2019;11:781-4. 